Article

\title{
Development and Validation of a Safety Attitude Scale for Coal Miners in China
}

\author{
Xiang $\mathrm{Wu}^{1,2}$, Wenwen Yin ${ }^{3}$, Chunlin $\mathrm{Wu}^{4,5, *}$ and Yuanlong $\mathrm{Li}^{1}$ \\ 1 School of Engineering and Technology, China University of Geosciences (Beijing), Beijing 100083, China; \\ wuxiang@cugb.edu.cn (X.W.); 2102170092@cugb.edu.cn (Y.L.) \\ 2 Key Laboratory of Deep Geodrilling Technology, Ministry of Land and Resources, Beijing 100083, China \\ 3 Department of Engineering Physics, Tsinghua University, Beijing 100084, China; \\ yww17@mail.tsinghua.edu.cn \\ 4 School of Economics and Management, Beihang University, Beijing 100191, China \\ 5 Beijing Key Laboratory of Emergency Support Simulation Technologies for City Operations, \\ Beihang University, Beijing 100191, China \\ * Correspondence: wuchunlin@buaa.edu.cn; Tel.: +86-10-82317839
}

Received: 26 October 2017; Accepted: 21 November 2017; Published: 27 November 2017

\begin{abstract}
Safety attitude is of vital importance to accident prevention, and the high accident rate in the coal mining industry makes it urgent to undertake research on coal miners' safety attitude. However, the current literature still lacks a valid and reliable safety attitude measurement scale for coal miners, which stands as a barrier against their safety attitude improvement. In this study, a scale is developed that can be used to measure coal miners' safety attitude. The preliminary scale was based on an extended literature review. Empirical data were then collected from 725 coal miners using the preliminary scale. Both exploratory and confirmatory factor analyses were undertaken to validate and improve the scale. The final scale, which consists of 17 items, contains four dimensions: management safety commitment, team safety climate, fatalism and work pressure. Results show that this safety attitude scale can effectively measure the safety attitude of coal miners, showing high psychological measurement validity. This paper contributes to the occupational safety research by developing the factor structure and indicator system of coal miners' safety attitude, thus providing more profound interpretation of this crucial construct in the safety research domain. The measurement scale serves as an important tool for safety attitude benchmarking among different coal mining enterprises and, thus, can boost the overall safety improvement of the whole industry. These findings can facilitate improvement of both theories and practices related to occupational safety attitude.
\end{abstract}

Keywords: safety attitude; measurement scale; coal miners; exploratory factor analysis; confirmatory factor analysis

\section{Introduction}

Coal mining is one of the riskiest industries [1]. In recent years, mining-related accidents have accounted for a significant proportion of all industrial accidents. Studies show that the main cause is unsafe working practices [2]. Employees with a good safety attitude will reduce these unsafe behaviors, thus avoiding preventable accidents without the need for supervision [3]. Lund and Aaro argued that by changing attitudes and then changing behaviors, accidents can be ultimately prevented [4]. Therefore, altering miners' safety attitude has become an important means of accident prevention $[5,6]$.

Safety attitude reflects the employees' beliefs and feelings about safety policies and measures [7]. It is an area of interdisciplinary research, connected with fields such as safety science, psychology and management science. The dimensions of safety attitude and its measurement by scales are important aspects of such research. The structure of safety attitude was initially proposed by Cox and Cox [8], 
who believed that objects of safety attitude were composed of four parts, i.e., safety hardware and physical hazards, safety software and concepts, people and risk. Accordingly, they proposed five dimensions of safety attitude. They pointed out that the structure of safety attitude can provide strategies for strengthening organizational safety culture, and a safety attitude scale can be used as a staff assessment method [8].

To date, researchers have developed a number of different scales to measure safety attitude. For example, Cox and Cox designed an effective method to survey a gas company's employees according to the objects of safety attitude [8]. Moreover, in the aviation field, Ford et al. designed a scale containing four dimensions to measure the safety attitude of flight attendants [9]. In the medical field, Haerkens et al. designed a six-dimension scale for measuring safety attitude, which included teamwork climate, job satisfaction and pressure recognition [10]. Smits et al. verified the reliability of a safety attitude scale used in the primary care setting, which contained five different factors [11]. Zhang developed a safety attitude scale for the manufacturing industry when studying the correlation between safety attitude and safety performance [12]. Each item of the scale contained three elements of attitude, i.e., cognition, emotion and behavioral tendency. Hui et al. measured food handlers' attitudes towards food safety through a scale of 14 items [13]. Zhang et al. studied the safety attitude of senior managers in the coal mining industry and concluded that it played a very important role in the safe operation of a mining organization [14].

Findley et al. pointed out that various safety management models and concerns over different types of risky work environments can lead to a variety of safety attitudes [15]. As stated above, it can be concluded from previous studies that different industries will require different safety attitude scales, and safety attitude surveys have been conducted in various industries, such as transportation, construction and food processing. However, despite the coal mining industry being one of the most dangerous industries in the world $[16,17]$, no safety attitude scale has been developed for this industry. The lack of a valid and reliable safety attitude scale not only undermines a scientific understanding of this crucial antecedent of safety performance, but also stands as a barrier against favorable safety attitude cultivation in practice. The adverse impacts for both academia and practitioners will ultimately hinder continuous safety improvement of this highly risky industry. Therefore, the purpose of this paper is to develop an effective tool to measure the safety attitude of coal miners and thus provide valid guidance for future research regarding coal mining accident prevention and safety performance improvement.

\section{Theoretical Basis and Research Hypothesis}

Currently, methodologies such as questionnaire survey, literature review, interview and report measurement are widely used by existing literature to determine the structure of safety attitude. Generally, an expert interview can be used to ensure the rationality of the safety attitude structure, and a questionnaire survey can be used to investigate the factor structure or structural dimensions of safety attitude through random sampling. These methods can ensure the validity and reliability of the dimensions of safety attitude. As a result, this study analyzed the safety attitude structure proposed in previous studies through a literature review. This was then combined with interviews to obtain the dimensions of coal miners' safety attitude, and finally, a preliminary safety attitude measurement scale was designed for such workers. Empirical data were obtained through a questionnaire survey and were then analyzed through exploratory factor analysis (EFA) and confirmatory factor analysis (CFA). In particular, EFA was applied to extract safety attitude dimensions quantitatively with empirical data. CFA, on the other hand, was used to check and improve the validity and reliability of the factor structure of safety attitude. The factor analysis methods ultimately led to the final version of the coal miners' safety attitude scale. 


\subsection{Preliminary Development of Scale}

This study used a questionnaire to make an empirical investigation. The questionnaire items rated safety attitude on a five-point Likert scale ranging from $1=$ "strongly disagree" to $5=$ "strongly agree". At the beginning of the questionnaire, the rationale for the questionnaire survey and instructions for answering each question were provided. In the first draft of the scale design, the structural dimensions of safety attitude according to the previous studies were explored, and items were developed based on these dimensions.

After reviewing previous research related to the safety attitude factor structure, it was found that, although the specific dimensions of safety attitude vary, they generally derived from the objects of safety attitude $[8,18,19]$. They are outlined in detail as follows:

1. Management safety commitment: The objects of safety attitude are safety software and concepts, which include safety laws and regulations, along with safety management. Rundmo and Hale [20] pointed out that managerial attitudes affect managers' decisions, employees' safety attitudes and the company's policies and safety status. Similarly, in the coal mining industry, managers' safety attitudes have a significant impact on those of coal miners.

2. Team safety climate: In the coal mining industry, the team is the basic unit of coal production and forms the entire coal mine production unit. The coal miners will affect the attitudes of others in the team, and the attitude of one person can easily lead to their partaking in illegal operations, followed by other team members behaving in a similar manner. Therefore, the creation of a good atmosphere in the team will help to promote safe coal mining practices.

3. Fatalism: Fatalism is a factor used to explain occupational accidents, as employees who have a fatalist attitude believe that accidents are caused by "fate" [21]. Therefore, a fatalist attitude reduces the importance of safety precautions for coal miners and can lead to accidents.

4. Work pressure: Recent research has shown that the pressure of work has a considerable influence on an employee's safety behavior [22]. Britt et al. believed that a high level of pressure will seriously affect workers' physical and mental health and behavior choices and can make them extremely prone to accidents [23].

5. Risk awareness: The related attitudes include attitude toward personal risks and control of risky behaviors. If the coal miners have negative attitudes towards risks and if they cannot identify the risks caused by mistakes, accidents will probably occur, whereas coal miners with a good sense of risk and of risk prevention will reduce the occurrence of such accidents.

6. Personal safety responsibility: In the coal mining industry, the proportion of human-related accidents has reached $90 \%$, and the unsafe practice of coal miners is one of the major causes of these accidents; moreover, illegal operation is a primary example of unsafe practices. However, if coal miners have a strong sense of responsibility and abide by laws, regulations and rules, a large number of accidents could be avoided.

Therefore, this study initially proposed six theoretical dimensions of coal miners' safety attitude, i.e., management safety commitment, team safety climate, fatalism, work pressure, risk awareness and personal safety responsibility.

The scale items were based on the work of Donald and Canter [24], and each item contained one of the safety attitude's three elements. Furthermore, some items also referred to the studies of Cox and Cox [8] and Williamson et al. [25]. The scale has 49 questions overall. Specifically, management safety commitment contains 12 questions, mainly involving behavioral tendencies; team safety climate contains seven questions, involving all three elements; fatalism contains six questions, mainly involving cognitive factors; work pressure contains eight questions, mainly involving emotional factors; risk awareness contains eight questions, mainly involving cognitive and emotional factors; and personal safety responsibility contains eight questions, mainly involving behavioral tendencies. It should be noted that proposing the six theoretical dimensions is mainly for identifying the items of 
the preliminary questionnaire. They may not be the final safety dimensions. Only with the validation of EFA and CFA can the final version of the scale be determined.

\subsection{Sample and Procedures}

The questionnaire survey was divided into two stages. In the first stage, the preliminary scale built above was distributed to a sample of the population. We connected safety managers in these four enterprises and distributed the safety attitude questionnaires to them, where safety managers explained the questionnaire to their employees. After these enterprises completed the survey, the safety managers screened the questionnaires and returned them. EFA was then used to analyze the responses received in order to improve the preliminary scale (hereafter, called the improved scale). In the second stage, the improved scale was distributed to a wider sample of the population. In order to confirm the reliability of the improved scale, CFA was used to analyze the responses. Moreover, some were also published online in the second stage.

Respondents of the questionnaire survey come from four different coal-mining enterprises in three different provinces, including Shanxi, Inner Mongolia and Anhui Provinces. By this means, research samples would be more representative and can thus be generalized throughout China. Consequently, 1208 questionnaires in total were received (400 in the first stage, 808 in the second stage), of which 725 were valid (valid questionnaires have no missing values regarding items related to safety attitude).

In the first stage, 132 valid questionnaires were received, resulting in a response rate of $33 \%$. This response rate is a bit lower than that in the second stage, mainly because the communication between the safety managers was not in place then, and thus, we did not conduct timely and effective collection of the completed questionnaires. However, we solved this problem effectively in the second stage and thus obtained a much higher response rate. The age of the valid respondents ranges from 21 to 55 years old (number $(\mathrm{N})=132$, mean $(\mathrm{M})=36.18$, standard deviation $(\mathrm{SD})=8.08$ ), and working years range from 1 to 26 years $(\mathrm{N}=132, \mathrm{M}=5.90, \mathrm{SD}=3.96)$. For educational background, $17 \%$ have primary education, $42 \%$ have secondary education, $27 \%$ have senior high school education and $14 \%$ hold a bachelor's degree. The respondents were all male.

In the second stage, 593 valid questionnaires were received. The age of the valid respondents ranges from 21 to 58 years old $(\mathrm{N}=575, \mathrm{M}=32, \mathrm{SD}=7.39)$, and working years range from 1 to 38 years $(\mathrm{N}=587, \mathrm{M}=5.75, \mathrm{SD}=5.21)$. For education background, $1.1 \%$ have primary education, $23.4 \%$ have secondary education, $40.7 \%$ senior high school education and $38.1 \%$ hold a bachelor's degree. The samples were all male.

\section{Results and Analysis}

\subsection{Exploratory Factor Analysis}

The six dimensions mentioned above are based on the literature research, but may not be applicable to the coal mining industry. Thus, the EFA is used to examine the dimensions. All the criteria in the following tests are based on the work of Wu [26], Hair et al. [27] and Schreiber [28], unless specified otherwise. The significance level was set at 0.05 .

In the first phase of the survey, a total of 400 questionnaires was received initially, out of which $132(33 \%)$ were valid. An EFA on the collected data was initially carried out using Statistical Product and Service Solutions (SPSS) 22.0 (International Business Machines Corporation, New York, NY, USA). The critical ratio (CR) technique was used to estimate the discrimination of each item. Principal component analysis (PCA) and Varimax rotation were also used to extract common factors. The number of common factors was determined using the eigenvalue $(>1)$ and scree plot test. Factor loading and communality were used to determine whether the item should be deleted. Finally, Cronbach's $\alpha$ was used to estimate the internal consistency of the scale.

Twenty-five items of the scale were worded to reflect a positive safety attitude, while the remaining 24 items were worded to reflect a passive safety attitude. These remaining 24 items were reversely 
scored to ensure all items were being measured in the same manner. Finally, the scores of all items were added together to get the total scores of the scale, which were ranked from high to low. The first $27 \%$ were chosen as the highest score group, and the last $27 \%$ were chosen as the lowest score group. An independent-sample $t$-test was used to analyze the empirical data. The $t$-value was viewed as a $\mathrm{CR}$, and those items whose $t$-values were less than three $(p>0.05)$ were deleted. Eventually, 26 items were retained.

The subsequent scale, consisting of 26 items, was considered to be a new scale, and factor analysis was used to obtain common factors. The measure of sampling adequacy (MSA) was used to estimate whether each item was appropriate for the ongoing factor analysis. The MSA should be greater than 0.5 . The MSA result of these items ranges from 0.595 to 0.909 (>0.5). Furthermore, the Kaiser-Meyer-Olkin (KMO) coefficient and Bartlett's test were used to assess whether the data of the whole scale were suitable for factor analysis. The KMO coefficient is $0.785(>0.6)$, and the chi-square statistic is significant $\left(\chi^{2}=2359.519\right.$, degrees of freedom (d.f.) $\left.=325, p<0.001\right)$, which demonstrates the suitability of the dataset for factor analysis. Next, PCA and Varimax rotation were employed to analyze the data. Common factors whose eigenvalue are greater than one were retained, and according to the scree plot, six common factors were obtained in this study. Their eigenvalues were 7.566, 4.359, 2.235, 2.031, 1.312 and 1.128 , respectively. These common factors account for $71.6 \%$ of the variance in total. However, some items were deleted based on the following principles: (a) the communality value is less than 0.2 ; (b) the factor loading value is less than 0.5 , which is higher than the standard of Cox and Cox [8] $(<0.4)$; and (c) any item for which it is difficult to refer to as a common factor. For example, the first factors contain some factors related to fatalism, risk awareness and personal safety responsibility, respectively. The item "I would go to work even if I was not trained" is related to personal safety responsibility, which leads to a situation where the first common factor could not be named as such; therefore, it was deleted. Additionally, the item "I believe an accident would happen to me if I worked underground" is related to risk awareness and similar to the item "whatever I do, an accident won't be prevented", which is related to fatalism; therefore, they were also deleted. Finally, the study obtained a scale (i.e., the improved scale) consisting of five dimensions: management safety commitment (MSC), team safety climate (TSC), fatalism (F), work pressure (WP) and personal safety responsibility (PSR). These dimensions account for $71.33 \%$ of the total variance. The result is provided in Table 1.

Table 1. The result of the factor analysis.

\begin{tabular}{|c|c|c|c|c|c|c|}
\hline \multirow{2}{*}{ Items } & \multicolumn{5}{|c|}{ Factor Loading } & \multirow{2}{*}{ Communality } \\
\hline & MSC & F & PSR & WP & TSC & \\
\hline $\begin{array}{l}\text { A1: All of the machinery is equipped with } \\
\text { a safeguard }\end{array}$ & 0.70 & & & & & 0.50 \\
\hline $\begin{array}{l}\text { A2: Management provide us with excellent } \\
\text { personal protective devices }\end{array}$ & 0.73 & & & & & 0.55 \\
\hline $\begin{array}{l}\text { A3: Management communicate with us about } \\
\text { safety frequently, and we can speak out freely }\end{array}$ & 0.85 & & & & & 0.73 \\
\hline $\begin{array}{l}\text { A4: Management legislate safety regulations, } \\
\text { which are suitable for our work, and demand } \\
\text { that we comply fully with these regulations }\end{array}$ & 0.68 & & & & & 0.57 \\
\hline A5: Management care about our safety & 0.70 & & & & & 0.51 \\
\hline $\begin{array}{l}\text { A6: An accident won't be prevented, even if } \\
\text { management take actions to prevent it }\end{array}$ & & 0.81 & & & & 0.76 \\
\hline $\begin{array}{l}\text { A7: An accident won't be prevented due to the } \\
\text { poor work environment }\end{array}$ & & 0.89 & & & & 0.82 \\
\hline $\begin{array}{l}\text { A8: An accident won't be prevented due to the } \\
\text { need to use machinery }\end{array}$ & & 0.86 & & & & 0.81 \\
\hline $\begin{array}{l}\text { A9: Whatever I do, an accident won't } \\
\text { be prevented }\end{array}$ & & 0.83 & & & & 0.79 \\
\hline
\end{tabular}


Table 1. Cont.

\begin{tabular}{|c|c|c|c|c|c|c|}
\hline \multirow{2}{*}{ Items } & \multicolumn{5}{|c|}{ Factor Loading } & \multirow{2}{*}{ Communality } \\
\hline & MSC & $\mathbf{F}$ & PSR & WP & TSC & \\
\hline $\begin{array}{l}\text { A10: The occurrence of an accident is down to } \\
\text { probability, therefore we should just trust } \\
\text { our luck }\end{array}$ & & 0.84 & & & & 0.81 \\
\hline $\begin{array}{l}\text { A11: Good production techniques do not lead to } \\
\text { unsafe behavior }\end{array}$ & & 0.69 & & & & 0.82 \\
\hline $\begin{array}{l}\text { A12: Each employee plays a significant role in } \\
\text { safe production }\end{array}$ & & & & & 0.68 & 0.68 \\
\hline $\begin{array}{l}\text { A13: If someone disobeys regulations, he would } \\
\text { be reminded of his obligations by co-workers }\end{array}$ & & & & & 0.62 & 0.74 \\
\hline $\begin{array}{l}\text { A14: We would help each other if we got } \\
\text { into trouble }\end{array}$ & & & & & 0.72 & 0.73 \\
\hline $\begin{array}{l}\text { A15: If co-workers disobeyed a safety regulation, } \\
\text { I would follow them }\end{array}$ & & & & & 0.80 & 0.84 \\
\hline A16: The workload makes me bored & & & & 0.71 & & 0.75 \\
\hline $\begin{array}{l}\text { A17: The regulations underground are tedious, } \\
\text { which makes people unnecessarily nervous }\end{array}$ & & & & 0.59 & & 0.68 \\
\hline $\begin{array}{l}\text { A18: The work underground is simple and } \\
\text { repetitive, which causes me to become bored } \\
\text { A19: There is a high temperature and high }\end{array}$ & & & & 0.77 & & 0.74 \\
\hline $\begin{array}{l}\text { humidity underground, which makes } \\
\text { me uncomfortable }\end{array}$ & & & & 0.83 & & 0.70 \\
\hline $\begin{array}{l}\text { A20: Safety is my own business, it has nothing to } \\
\text { do with anyone else }\end{array}$ & & & 0.72 & & & 0.71 \\
\hline $\begin{array}{l}\text { A21: I will operate according to my } \\
\text { own experience }\end{array}$ & & & 0.80 & & & 0.75 \\
\hline Eigenvalue & 6.36 & 3.54 & 1.99 & 1.89 & 1.20 & \\
\hline Cumulative $\%$ of explanatory variance & 30.27 & 47.10 & 56.59 & 65.61 & 71.33 & \\
\hline
\end{tabular}

Note: MSC, management safety commitment; TSC, team safety climate; F, fatalism; WP, work pressure; PSR, personal safety responsibility.

The correlation coefficients of these dimensions range from 0.00 to 0.60 , which demonstrates that they are independent of each other to a certain extent. The correlation coefficient between each dimension and the entire scale ranges from 0.39 to $0.76(p<0.01)$, which demonstrates that each dimension corresponds to the whole scale. The correlation coefficients are provided in Table 2.

Table 2. The result of the correlation analysis.

\begin{tabular}{|c|c|c|c|c|c|c|}
\hline & F & MSC & TSC & PSR & WP & Scale \\
\hline $\mathrm{F}$ & 1 & & & & & $0.76^{* *}$ \\
\hline MSC & 0.04 & 1 & & & & $0.44^{* *}$ \\
\hline TSC & 0.00 & $0.44^{* *}$ & 1 & & & $0.39^{* *}$ \\
\hline PSR & 0.60 ** & -0.01 & 0.17 & 1 & & $0.63^{* *}$ \\
\hline WP & 0.39 ** & 0.02 & 0.09 & $0.41^{* *}$ & 1 & $0.63^{* *}$ \\
\hline Scale & $0.76^{* *}$ & $0.44^{* *}$ & $0.39^{* *}$ & $0.63^{* *}$ & $0.63^{* *}$ & 1 \\
\hline
\end{tabular}

Cronbach's $\alpha$ for the entire scale is 0.89 and that of the dimensions range from 0.65 to 0.93 , as shown in Table 3. This result is ideal. Therefore, using EFA, the improved scale was developed with a total of 21 questions to measure the safety attitude of coal miners. The scale consists of five dimensions, i.e., management safety commitment, team safety climate, fatalism, work pressure and personal safety responsibility. 
Table 3. Cronbach's $\alpha$ of the scale.

\begin{tabular}{ccccccc}
\hline & F & MSC & PSR & WP & TSC & Scale \\
\hline Cronbach's $\alpha$ & 0.93 & 0.78 & 0.89 & 0.77 & 0.65 & 0.89 \\
Number of items & 6 & 5 & 2 & 4 & 4 & 21 \\
\hline
\end{tabular}

\subsection{Confirmatory Factor Analysis}

The improved scale was obtained after the first phase of the analysis and then distributed to more respondents. The empirical data collected were further analyzed by CFA to verify the scale. In addition, the improved scale was also posted on social media to invite miners to complete the scale.

The second survey obtained 808 responses, 593 of which were valid. CFA was performed on the data gathered from the second survey using Amos 20.0. When maximum likelihood was adopted to analyze the data, the variances of the five dimensions were seen as one. However, the result indicates that the factor loadings of the three items, "The occurrence of an accident is down to probability, therefore we should just trust our luck" (A10), "Good production techniques do not lead to unsafe behavior" (A11) and "I will operate according to my own experience" (A20), are 0.385, 0.052 and 0.391, respectively. These three items were deleted as a result of being below 0.4. After this, it was found that in each project, the factor loading is between 0.562 and 0.888 , and the CR of the path coefficient is between 12.966 and 26.410. The measure of the significance level, $p$, is less than 0.001 , and the path coefficient is significant, indicating that these path coefficient parameters are significantly different. The coefficient values are provided in Table 4.

Table 4. The regression weights.

\begin{tabular}{ccccc}
\hline & Estimate & Standard Error & Critical Ratio & $p$-Value \\
\hline A1 $\leftarrow$ MSC & 0.573 & 0.031 & 18.522 & $* * *$ \\
A2 $\leftarrow$ MSC & 0.821 & 0.037 & 22.134 & $* * *$ \\
A3 $\leftarrow$ MSC & 0.941 & 0.038 & 24.571 & $* * *$ \\
A4 $\leftarrow$ MSC & 0.680 & 0.034 & 19.855 & $* * *$ \\
A5 $\leftarrow$ MSC & 0.769 & 0.037 & 20.771 & $* * *$ \\
A6 $\leftarrow$ F & 0.909 & 0.045 & 20.109 & $* * *$ \\
A7 $\leftarrow$ F & 1.092 & 0.041 & 26.410 & $* * *$ \\
A8 $\leftarrow$ F & 1.049 & 0.042 & 25.202 & $* * *$ \\
A9 $\leftarrow$ F & 0.749 & 0.042 & 17.758 & $* * *$ \\
A12 $\leftarrow$ TSC & 0.581 & 0.040 & 14.411 & $* * *$ \\
A13 $\leftarrow$ TSC & 0.474 & 0.032 & 14.735 & $* * *$ \\
A14 $\leftarrow$ TSC & 0.546 & 0.042 & 12.966 & $* * *$ \\
A15 $\leftarrow$ TSC & 0.582 & 0.036 & 16.089 & $* * *$ \\
A16 $\leftarrow$ WP & 1.041 & 0.042 & 24.827 & $* * *$ \\
A17 $\leftarrow$ WP & 0.774 & 0.044 & 17.487 & $* * *$ \\
A18 $\leftarrow$ WP & 0.916 & 0.043 & 21.478 & $* * *$ \\
A19 $\leftarrow$ WP & 1.014 & 0.044 & 23.182 & \\
A21 $\leftarrow$ PSR & 0.811 & 0.050 & 16.158 &
\end{tabular}

An ideal model should meet the requirements that GFI (goodness of fit index) is greater than 0.90, AGFI (adjusted goodness of fit index) is greater than 0.90, RMSEA (Root mean square error of approximation) is less than 0.08 and CFI (comparative fitness index) is greater than 0.90 . Schreiber et al. indicated that the Tucker-Lewis index (TLI), CFI and RMSEA were important fit indicators to confirm the validity of a model [28]. However, they thought that TLI should be greater than $0.95, \mathrm{CFI}$ should be greater than 0.95 and RMEA should be less than 0.08. At first, the results of the research did not fit the ideal model, so MI (modification index) $(>20)$ was used to modify it. The results indicated that the MI between Item 9 and PSR is 45.36, and the MI between Item 13 and Item 21 is 50.11, which proved that Item 9 is related to PSR, and Item 13 is related to Item 21. However, Item 9 is an indicator of F, Item 13 
an indicator of SA and Item 21 an indicator of PSR, all of which leads to the conclusion that the model could not be classified as acceptable. Furthermore, the PSR dimension has only two indicators at that stage, which cannot reflect a latent variable. The authors therefore deleted this dimension. Having deleted the PSR dimension, the subsequent results demonstrate that the model is acceptable. The fit indicators are as follows: $\chi^{2}=380.662\left(p=0.000<0.05, \chi^{2} /\right.$ d.f. $\left.=2.86<3\right)$, GFI $=0.93$, AGFI $=0.91$, $\mathrm{TLI}=0.95, \mathrm{CFI}=0.96$ and $\mathrm{RMSEA}=0.06$. The result of the CFA is provided in Table 5 .

After the factor analysis was validated, unsuitable items were deleted, and a final scale consisting of 17 questions was developed to test the safety attitudes of coal miners. It contains four safety attitude dimensions, i.e., management safety commitment, team safety climate, fatalism and work pressure. The four dimensions constitute the framework of the factor structure and indicator system of coal miners' safety attitude. The final scale is provided in detail in Appendix A.

Table 5. The result of the confirmatory factor analysis (CFA).

\begin{tabular}{cccccccc}
\hline Model & $\chi^{2}$ (d.f.) & $\chi^{2}$ /d.f. & GFI & AGFI & TLI & CFI & RMSEA \\
\hline Ideal model & & $<3$ & $>0.90$ & $>0.90$ & $\geq 0.95$ & $\geq 0.95$ & $<0.08$ \\
SAS & 380.662 & 2.86 & 0.93 & 0.91 & 0.95 & 0.96 & 0.06
\end{tabular}

Note: *** indicate $p<0.001$; SAS, safety attitude scale. GFI, goodness-of-fit index; AGFI, adjusted goodness-of-fit index; TLI, Tucker-Lewis index; CFI, comparative fitness index; RMSEA, root mean square error of approximation.

\section{Discussion}

\subsection{Scale Development}

In the first stage of this study, a scale (i.e., the improved scale) was developed consisting of five dimensions. However, the result of EFA established that risk perception could not be categorized as one of the safety attitude dimensions. This meant that risk awareness is not an element of safety attitude. Rundmo and Hale indicated that risk awareness can be divided into the cognitive aspect and the emotional aspect [20]. When it comes to asking employees whether risk would result in accidents, it is a cognitive aspect, whereas the emotional aspect reflects the fact that employees feel unsafe and worried because of the risk existing in the work environment. However, the definition of safety awareness and the cognitive aspects of fatalism overlap to a certain extent. According to the above data analysis, fatalism can reflect the cognition of coal miners on accidents, and this is also associated with the characteristics of such workers. Coal miners generally have a low level of education ( $84 \%$ of the respondents have an education background below a bachelor's degree), lack risk consciousness and are likely to have a fatalist attitude. Furthermore, coal miners may know very little about the risks of their work environment, which results in a deficiency of risk-related emotions. Therefore, fatalism, which is similar to the cognitive composition of risk awareness, prevails among coal miners. However, in contrast to risk, the pressure of work caused their emotions to change. The work pressure dimension of this scale is based on the sources of pressure perceived by the coal miners. Britt et al. believed that excessive pressure would seriously and negatively affect the coal miners' physical and mental health, as well as behavior choice and would probably in turn lead to accidents occurring [23]. Therefore, there was a strong basis for integrating work pressure as a dimension of the scale.

Through the correlation analysis, it is found that the correlation between fatalism and the total score was the highest, indicating that fatalism can reflect the safety attitude of coal miners and also underlining the hypothesis that coal miners' education levels are generally low. The result of the correlation analysis demonstrates that the team safety climate and management safety commitment are weakly related to the safety attitude, which differed from the findings of other researchers $[29,30]$. However, the team safety climate and management safety commitment have a moderate correlation with each other, as both of them are explored from the "safety software and concept". Similarly, work pressure and personal safety responsibility have a moderate correlation with each other, and they are 
explored from "people". Fatalism is explored from "risk", but it is strongly related to personal safety responsibility. Fatalism reflects the belief of employees that accidents could not be prevented, whereas personal safety responsibility reflects the fact that employees would behave in an unsafe manner. The results demonstrate that if employees believe that accidents cannot be prevented, they would carry out unsafe working practices more frequently. In addition, the correlation between management safety commitment and team safety climate with other dimensions does not differ significantly, reflecting the safety attitude of different objects. The correlation between them may therefore be different.

The result of the EFA demonstrates that the structure of the scale can be accepted. The result of the reliability analysis shows that Cronbach's $\alpha$ of the entire scale is 0.873 , which demonstrates its high internal consistency. Cronbach's $\alpha$ of the five safety attitude dimensions ranges from 0.642 to 0.929 . Cronbach's $\alpha$ of fatalism is the highest $(\alpha=0.929$ ), which also proves that fatalism can fully reflect the safety attitude of coal miners. However, Cronbach's $\alpha$ of the team safety climate is the lowest $(\alpha=0.642)$.

\subsection{Scale Confirmation}

The path coefficients of the final scale are significant $(p<0.001)$, and the fit indicators all correspond with the indicators of an ideal model. Only TLI $=0.94(<0.95)$ is not accepted, apart from which, the model's structure has a good degree of correlation. Therefore, the final model is acceptable. After the EFA, an item was added to the team safety climate dimension, and the result of the CFA shows that the factor loading of the item is $0.619(>0.5)$. A10 and A20's factor loading values are less than 0.4 , so these two items were deleted. However, their factor loading values are very close to the limit 0.4 , and thus, in future research, we can also retain these items for further analysis to see if the path coefficient is significant to determine an items' deletion. Furthermore, the path coefficient between the item and team safety climate is significant $(p<0.001)$, which demonstrates that this item could be an indicator of the team safety climate dimension. However, the result also demonstrates that the personal safety responsibility dimension makes it impossible for the model to fit with the data, and when this dimension was deleted, the model fit with the data in a favorable manner. Moreover, the result of the CFA indicates that personal safety responsibility is strongly related to fatalism (the correlation coefficient was 0.596). However, as this may have affected the independence of the dimension, it is reasonable to delete the personal safety responsibility dimension. This is different from the scale developed by Cox and Cox [8], which may be caused by the differences between safety culture, management and characteristics of employees of different industries. However, the final scale is confirmed and proved to be a robust instrument for measuring coal miners' safety attitude.

\section{Conclusions and Implications}

Positive safety attitude plays an important role in improving unsafe behavior, so exploring the structure of the safety attitude and accurately measuring safety attitude can effectively improve the coal miners' safety attitude and thus improve safety performance. The theoretical contributions of this paper include the following two aspects:

- This paper contributes to the current occupational safety research by developing a valid and reliable factor structure of coal miners' safety attitude. Based on the objects of safety attitude, an effective safety attitude scale was obtained by systematically exploring the dimensions of safety attitude and designing items related to cognitive, emotional and behavioral tendencies. The safety attitude factor structure provides a more profound interpretation of this crucial construct in the safety research domain.

- A measurement scale has been developed that contains four dimensions, i.e., management safety commitment, team safety climate, fatalism and work pressure. There are 17 questions in total, and it demonstrates high validity and reliability (Appendix A). By providing a uniform measuring criterion, this scale will facilitate future safety attitude research both in the coal mining industry and other industries. 
Furthermore, specific practical implications of this paper include the following two aspects:

- The measurement scale serves as an important tool for safety attitude benchmarking among different coal mining enterprises and thus can boost overall safety improvement of the whole industry.

- According to the findings of the questionnaire survey, it is also recommended that the safety training and education of coal miners should be strengthened, the miners' work pressure should be reduced and managers' attention to safety should be increased. These are the most crucial measures to promote coal miners' safety attitudes currently.

The specific theoretical and practical implications will lead researchers and practitioners to pay more attention to safety attitude, in order to improve workers' behavior in the coal mining industry. These conclusions can serve as important strategies for the improvement of both theories and practices related to occupational safety attitude.

Acknowledgments: This work was supported financially by the National Natural Science Foundation of China (71572088), the Fundamental Research Funds for the Central Universities of China (2-9-2017-077) and the Key Laboratory of Toxic and Dust Hazards Prevention and Control Technology Fund Project (2018KFKT01). The authors would like to thank all the participants who completed the questionnaires.

Author Contributions: Xiang $\mathrm{Wu}$ and Wenwen Yin conceived of the key ideas and the system architecture. Chunlin Wu conducted the research. Wenwen Yin analyzed the data. Xiang Wu, Chunlin Wu and Yuanlong Li wrote the paper.

Conflicts of Interest: The authors declare no conflict of interest.

\section{Appendix A}

Table A1. Safety attitude scale.

\begin{tabular}{|c|c|c|}
\hline Dimensions & Codes & Items \\
\hline \multirow{5}{*}{$\begin{array}{l}\text { Management } \\
\text { safety } \\
\text { commitment }\end{array}$} & MSC1 & All of the machinery is equipped with a safeguard \\
\hline & MSC2 & Management provide us with excellent personal protective devices \\
\hline & MSC3 & $\begin{array}{l}\text { Management communicate with us about safety frequently, and we can speak } \\
\text { out freely }\end{array}$ \\
\hline & MSC4 & $\begin{array}{l}\text { Management legislate safety regulations, which are suitable for our work, and } \\
\text { demand that we comply fully with these regulations }\end{array}$ \\
\hline & MSC5 & Management care about our safety \\
\hline \multirow{4}{*}{ Fatalism } & F6 & An accident won't be prevented, even if management take actions to prevent it \\
\hline & F7 & An accident won't be prevented due to the poor work environment \\
\hline & F8 & An accident won't be prevented due to the need to use machinery \\
\hline & F9 & Whatever I do, an accident won't be prevented \\
\hline \multirow{4}{*}{$\begin{array}{l}\text { Team safety } \\
\text { climate }\end{array}$} & TSC10 & Each employee plays a significant role in safe production \\
\hline & TSC11 & $\begin{array}{l}\text { If someone disobeys regulations, he would be reminded of his obligations } \\
\text { by co-workers }\end{array}$ \\
\hline & TSC12 & We would help each other if we got into trouble \\
\hline & TSC13 & If co-workers disobeyed a safety regulation, I would follow them \\
\hline \multirow{4}{*}{ Work pressure } & WP14 & The workload makes me bored \\
\hline & WP15 & $\begin{array}{l}\text { The regulations underground are tedious, which makes people } \\
\text { unnecessarily nervous }\end{array}$ \\
\hline & WP16 & $\begin{array}{l}\text { The work underground is simple and repetitive, which causes me to } \\
\text { become bored }\end{array}$ \\
\hline & WP17 & $\begin{array}{l}\text { There is a high temperature and high humidity underground, which makes } \\
\text { me uncomfortable }\end{array}$ \\
\hline
\end{tabular}




\section{References}

1. Zhang, S.; Shi, X.; Wu, C. Measuring the effects of external factor on leadership safety behavior: Case study of mine enterprises in China. Saf. Sci. 2017, 93, 241-255. [CrossRef]

2. Sari, M.; Duzgun, H.S.B.; Karpuz, C.; Selcuk, A.S. Accident analysis of two Turkish underground coal mines. Saf. Sci. 2004, 42, 675-690. [CrossRef]

3. Eid, J.; Mearns, K.; Larsson, G.; Laberg, J.C.; Johnsen, B.H. Leadership, psychological capital and safety research: Conceptual issues and future research questions. Saf. Sci. 2012, 50, 55-61. [CrossRef]

4. Lund, J.; Aaro, L.E. Accident prevention. Presentation of a model placing emphasis on human, structural and cultural factors. Saf. Sci. 2004, 42, 271-324. [CrossRef]

5. Bergheim, K.; Nielsen, M.B.; Mearns, K.; Eid, J. The relationship between psychological capital, job satisfaction, and safety perceptions in the maritime industry. Saf. Sci. 2015, 74, 27-36. [CrossRef]

6. Nasab, H.S.; Ghofranipour, F.; Kazemnejad, A.; Khavanin, A.; Tavakoli, R. Evaluation of Knowledge, Attitude and Behavior of Workers towards Occupational Health and Safety. Iran. J. Public Health 2009, 38, 125-129.

7. Henning, J.B.; Stufft, C.J.; Payne, S.C.; Bergman, M.E.; Mannan, M.S.; Keren, N. The influence of individual differences on organizational safety attitudes. Saf. Sci. 2009, 47, 337-345. [CrossRef]

8. Cox, S.; Cox, T. The structure of employee attitudes to safety: A European example. Work Stress 1991, 5, 93-106. [CrossRef]

9. Ford, J.; Henderson, R.; O'Hare, D. The effects of Crew Resource Management (CRM) training on flight attendants' safety attitudes. J. Saf. Res. 2014, 48, 49-56. [CrossRef] [PubMed]

10. Haerkens, M.H.; Leeuwen, W.V.; Sexton, J.B.; Pickkers, P.; van der Hoeven, J.G. Validation of the Dutch language version of the Safety Attitudes Questionnaire. BMC Health Serv. Res. 2016, 16, 385-392. [CrossRef] [PubMed]

11. Smits, M.; Keizer, E.; Giesen, P.; Deilkås, E.C.T.; Hofoss, D.; Bondevik, G.T. The psychometric properties of the 'safety attitudes questionnaire' in out-of-hours primary care services in the Netherlands. PLoS ONE 2017, 12, e0172390. [CrossRef] [PubMed]

12. Zhang, R. The interaction mechanism between the safety attitude and safety performance. In Proceedings of the International Conference on Economics, Social Science, Arts, Education and Management Engineering, Xi'an, China, 12-13 December 2015; Atlantis Press: Paris, France, 2015; pp. 634-638.

13. Lee, H.K.; Halim, H.A.; Thong, K.L.; Chai, L.C. Assessment of Food Safety Knowledge, Attitude, Self-Reported Practices, and Microbiological Hand Hygiene of Food Handlers. Int. J. Environ. Res. Public Health 2017, 14, 55. [CrossRef]

14. Zhang, J.; Chen, N.; Fu, G.; Yan, M.; Kim, Y.C. The Safety Attitudes of Senior Managers in the Chinese Coal Industry. Int. J. Environ. Res. Public Health 2016, 13, 1147. [CrossRef] [PubMed]

15. Findley, M.; Smith, S.; Gorski, J.; O'neil, M. Safety climate differences among job positions in a nuclear decommissioning and demolition industry: Employees' self-reported safety attitudes and perceptions. Saf. Sci. 2007, 45, 875-889. [CrossRef]

16. Deng, M.; Chan, A.H.; Wu, F.; Sun, L. Depth perception, dark adaptation, vigilance and accident proneness of Chinese coal mine workers. Int. J. Occup. Saf. Ergon. 2016, 22, 1-7. [CrossRef] [PubMed]

17. Niczyporuk, Z.T. Safety Management in Coal Mines-Risk Assessment. Int. J. Occup. Saf. Ergon. 1996, 2, 243-250. [CrossRef] [PubMed]

18. Cheyne, A.; Oliver, A.; Tomás, J.M.; Cox, S. The architecture of employee attitudes to safety in the manufacturing sector. Pers. Rev. 2002, 31, 649-670. [CrossRef]

19. Rundmo, T. Safety climate, attitudes and risk perception in Norsk Hydro. Saf. Sci. 2000, 34, 47-59. [CrossRef]

20. Rundmo, T.; Hale, A.R. Managers' attitudes towards safety and accident prevention. Saf. Sci. 2003, 41, 557-574. [CrossRef]

21. Patwary, M.A.; O'Hare, W.T.; Sarker, M.H. Occupational accident: An example of fatalistic beliefs among medical waste workers in Bangladesh. Saf. Sci. 2012, 50, 76-82. [CrossRef]

22. Nahrgang, J.D.; Morgeson, F.P.; Hofmann, D.A. Safety at work: A meta-analytic investigation of the link between job demands, job resources, burnout, engagement, and safety outcomes. J. Appl. Psychol. 2011, 96, 71-94. [CrossRef] [PubMed]

23. Britt, T.W.; Castro, C.A.; Adler, A.B. Self-engagement, stressors, and health: A longitudinal study. Pers. Soc. Psychol. Bull. 2005, 31, 1475-1486. [CrossRef] [PubMed] 
24. Donald, I.; Canter, D. Employee attitudes and safety in the chemical industry. J. Loss Prev. Process Ind. 1994, 7, 203-208. [CrossRef]

25. Williamson, A.; Feyer, A.M.; Cairns, D.; Biancotti, D. The development of a measure of safety climate: The role of safety perceptions and attitudes. Saf. Sci. 1997, 25, 15-27. [CrossRef]

26. Wu, M.L. Questionnaire Statistical Analysis Practice-SPSS Operation and Application; Chongqing University Press: Chongqing, China, 2010; pp. 123-146.

27. Hair, J.F.; Black, W.C.; Babin, B.J.; Anderson, R.E.; Tatham, R.L. Multivariate Data Analysis: A Global Perspective; Prentice-Hall Press: Upper Saddle River, NJ, USA, 2010; pp. 12-15.

28. Schreiber, J.B.; Nora, A.; Stage, F.K.; Barlow, E.A.; King, J. Reporting Structural Equation Modeling and Confirmatory Factor Analysis Results: A Review. J. Educ. Res. 2006, 99, 323-338. [CrossRef]

29. Burns, C.; Mearns, K.; Mcgeorge, P. Explicit and implicit trust within safety culture. Risk Anal. 2006, 26, 1139-1150. [CrossRef] [PubMed]

30. Burt, C.D.B.; Sepie, B.; Mcfadden, G. The development of a considerate and responsible safety attitude in work teams. Saf. Sci. 2008, 46, 79-91. [CrossRef]

(C) 2017 by the authors. Licensee MDPI, Basel, Switzerland. This article is an open access article distributed under the terms and conditions of the Creative Commons Attribution (CC BY) license (http:/ / creativecommons.org/licenses/by/4.0/). 